\title{
A interculturalidade da doçaria brasileira sob a perspectiva de Gilberto Freyre
}

\author{
The interculturality of Brazilian sweets from the perspective of Gilberto Freyre
}

\author{
Rosana Eduardo da Silva Leal
}

Universidade Federal de Sergipe - UFS - Sergipe - Brasil

\begin{abstract}
Resumo: Os saberes culinários apresentam-se como mecanismos de adaptação humana ao ambiente vivido. São responsáveis por promover o diálogo entre a natureza e a cultura, tendo a capacidade de exprimir crenças, hábitos e costumes de grupos e sociedades. Neste contexto, podemos situar uma culinária tradicional que se desenvolveu a partir do cultivo da cana-açúcar no Brasil, iniciado no século $\mathrm{XVI}$, que influenciou decisivamente o paladar dos brasileiros. Com pitadas ameríndias, portuguesas e africanas, o açúcar logo se solidificou na culinária brasileira misturando-se aos alimentos nativos, transformando-se em uma das especiarias mais utilizadas na terra brasilis. A iguaria gerou uma singular "cultura do doce", como denominou Freyre (2007 [1939]), resultante da inventividade e criatividade de distintas etnias e grupos sociais. É sobre este universo que tratará o artigo, que buscará analisar as reflexões de Gilberto Freyre, importante antropólogo brasileiro, em seu livro "Açúcar", traçando as influências, misturas e produções socioculturais que deram base à doçaria do Brasil. Apresentaremos também dados etnográficos sobre a culinária do açúcar presente na cidade histórica de São Cristóvão, um reduto de produção da doçaria tradicional tratada por Freyre.
\end{abstract}

Palavras-chave: Culinária. Interculturalidade. Doçaria.

\begin{abstract}
The culinary knowledge present as mechanisms for adaptation to the human living environment. They are responsible for promoting the dialogue between nature and culture, having the ability to express beliefs, habits and customs of groups and societies. In this context, we can situate a traditional cuisine that developed from sugar cane cultivation in Brazil, which began in the sixteenth century, which decisively influenced the taste of Brazilians. With pinches Amerindian, Portuguese and African, sugar immediately solidified in Brazilian cuisine blending the native foods, becoming one of the most used spices in brasilis land. The delicacy created a unique "sweet culture" as called Freyre (2007 [1939]), resulting from the inventiveness and creativity of different ethnic and social groups. It is this universe that treats the article, which seek to analyze the reflections of Gilberto Freyre, important Brazilian anthropologist, in his book "Sugar", tracing the influences, mixtures and socio-cultural productions that provided the basis for sweets in Brazil. Also present ethnographic data on the cuisine of this sugar in the historic town of Saint Kitts, a traditional pastry production stronghold treated by Freyre.
\end{abstract}

Keywords: Culinery. Interculturalism. Sweets. Gilberto Freyre. 


\section{Introdução}

Este artigo faz parte dos estudos realizados sobre a culinária do açúcar em Sergipe, que tem por base o pensamento de Gilberto Freyre. Desde 2010, a temática tem feito parte de ações acadêmicocientíficas realizadas no curso de Turismo da Universidade Federal de Sergipe - UFS, tendo como campo de pesquisa a cidade histórica de São Cristóvão-SE. Desde então, as ações de pesquisa foram contempladas com bolsas de iniciação científica (PIBIC e PIIC/UFS) que possibilitaram a produção de trabalhos de conclusão de curso, apresentações em eventos científicos, ações de extensão e publicação de artigos. A investigação está inserida na linha de pesquisa Cultura e Alimentação do Grupo de Pesquisa em Antropologia e Turismo ANTUR/UFS/CNPQ.

Em 2015 a pesquisa foi contemplada com bolsa para Estágio Pós-Doutoral na Universidad de Salamanca, através da agência brasileira CAPES Coordenação de Aperfeiçoamento de Pessoal de Nível Superior, com a finalidade de realizar estudo comparativo entre Sergipe/Brasil e Salamanca/Espanha. A intenção da proposta foi ampliar o escopo do estudo, possibilitando uma investigação bilateral, que contemplasse realidades no Brasil e na Espanha, considerando as dimensões patrimoniais e turísticas, bem como os processos de empreendedorismo endógeno presentes no contexto sociocultural e econômico da culinária do açúcar em Sergipe/Brasil e Salamanca/Espanha.

Neste âmbito, o presente artigo visa analisar a base intercultural da obra "Açúcar" de Gilberto Freyre, sociólogo e antropólogo brasileiro que teve suas obras mundialmente reconhecidas pelo valor histórico e etnográfico de seus escritos. No referido livro, Freyre nos apresenta como o intercâmbio de ingredientes, técnicas e saberes provenientes da presença indígena, africana e portuguesa

\footnotetext{
1 "Las relaciones interculturales no poseen carta de exclusividad disciplinaria, pero las diferentes explicaciones no pueden soslayar las posibilidades interpretativas de la antropología. Los conceptos de aculturación, transculturación, difusión o cambio cultural
}

transformou a culinária brasileira em uma expressiva produção intercultural, capaz de refletir processos identitários e étnicos. Para tanto, seguimos a perspectiva de Gómez \& Hernández (2010) quando salientam que as relações culturais são por natureza relações interculturais, uma vez que estão embasadas em interações sociais endógenas e exógenas. As endógenas são adquiridas pelo homem através do seu grupo social em processos de natureza interna em que absorve saberes, costumes, a língua, tradições, ritos e mitos. Já as exógenas se dão por meio do contato e relacionamento com outras culturas, através do comércio, da expansão territorial, intercâmbio de bens, alianças, entre outros aspectos. Segundo os referidos autores, os movimentos populacionais sempre geraram relações entre as culturais, independente das motivações de tais fluxos. Por isso, as relações interculturais estiveram presentes nas sociedades muito antes da globalização, uma vez que "cuando una sociedad o un grupo se relacionan con otros, invariablemente estamos ante la presencia de contacto cultural y con esto de relaciones interculturales" (GÓMEZ \& HERNÁNDEZ, 2010, p. 14). Conforme salientam os autores, a Antropologia ${ }^{1}$ tem documentado e interpretado continuamente estes processos de contato entre cultural, considerando as trocas e mudanças culturais, construindo conceitos e paradigmas como possibilidades explicativas de realidades sociais específicas.

Neste sentido, para a escrita deste texto, partimos do pressuposto que as obras de Gilberto Freyre possuem uma natureza essencialmente intercultural, na medida em que considera os intercâmbios, absorções e elaborações promovidos pelos processos de contato e miscigenação que construíram a sociedade brasileira.

Gilberto Freyre sempre aponta para as interpretações, os encontros de culturas, as transferências simbólicas dessas mesmas culturas, com relação ao Brasil,

refieren al proceso mediante el cual una cultura entra en contacto con otra, y producto de esta relación, ambas presentan diferentes tipos de cambios" (GÓMES \& HERNÁNDEZ, 2010, p.14). 
e com mais acuidade o Nordeste, e com mais amorosidade Pernambuco, e consegue transmitir os processos históricos, econômicos, sociais e civilizatórios (LODY, 2011, p.37).

O olhar de Freyre - cuja vertente é etnográfica, comparativa, regional e internacional perpassou questões do Brasil oficial e extraoficial, transitando pelas ruas, capelas, casas-grandes, senzalas, festas, praças, mercados públicos, terreiros de candomblé e procissões, dando conta da vida pública e privada brasileira. Freyre "procura sempre relacionar e relativizar as conversas das culturas, sem hierarquizar, contudo, buscando entender, melhor dizendo, traduzir as emergências de um povo em constante processo de construção das suas identidades" (LODY, 2011, p. 33). Nesta vertente freyreana, buscaremos ilustrar como a culinária intercultural do açúcar se faz presente no Nordeste brasileiro, por meio de dados etnográficos sobre a presença desta tradição na cidade história de São Cristóvão, em Sergipe, considerada importante reduto doceiro do estado.

\section{Por uma sociologia do doce}

A obra "Açúcar" teve sua primeira edição lançada em 1939 com o subtítulo "uma sociologia do doce, com receitas de bolos e doces do Nordeste do Brasil". O livro, que abordou uma temática pouco convencional para a época, reúne reflexões sobre a relação cotidiana do brasileiro com a doçaria local, permeando aspectos históricos, econômicos, sensoriais, culturais e estéticos. Para Freyre, "há uma sociologia do doce à parte de uma sociologia de arte da cozinha e do que esta arte - mais vasta - implica de sociocultural" (FREYRE, 2007 [1939]: 57).

Freyre parte do seguinte questionamento: "e quem hoje ignora o significado sociológico de doces ou quitutes como expressão de uma cultura regional

2"O Nordeste do Brasil, pelo prestígio quatro vezes secular da sua sub-região açucareira não só no conjunto regional, como no país inteiro, se apresenta como área brasileira por excelência do açúcar. Não só do açúcar: também a área por excelência do bolo aristocrático, do doce fino, da sobremesa fidalga tanto - ou nacional?" (FREYRE, 2007 [1939], p. 44). O livro faz parte do conjunto de escritos de Freyre envolvendo a defesa da culinária regional, definida pelo autor como uma obra sobre o "[...] regionalismo culinário especializado em doçaria" (FREYRE, 2007 [1939], p. 96). Tal pensamento também se faz notar em obras como Casa Grande \& Senzala, Nordeste e Sobrados \& Mucambos em que defende que a doçaria é um dos aspectos de maior originalidade no Brasil.

A obra é resultado das reflexões iniciadas pelo autor durante o Congresso Regionalista do Nordeste, ocorrido em 1926 no Recife, em que defendeu a culinária Nordestina e a necessidade de estudos sobre tal temática. Freyre inaugura no Brasil uma sociologia da alimentação, utilizando-se para isso a doçaria, que chamou de sociologia do doce, conforme defendeu em 1970, durante sua participação no programa do então Museu do Açúcar, no Recife:

Se não há - pode haver e, ao meu ver, estaria já em formação - uma sociologia do trigo, outra do vinho, ainda outra, da mandioca. Todo produto que seja, sob critério antropológico, a base de um complexo sociocultural de vida e de convivência humana, é suscetível de servir de objeto a uma sociologia especializada no seu estudo (FREYRE, 1971 apud ALCÂNTARA, 2011, p. 13).

Na obra, o autor identifica a presença de uma "geografia do doce" em que se destacam estados como Pernambuco, Rio de Janeiro, Pará e Rio Grande do Sul, mas destaca o Nordeste como a região onde se tem a presenta mais latente $\mathrm{e}$ inventiva desta arte culinária ${ }^{2}$. Para Freyre, o açúcar recortou o Nordeste como uma área de cultura em que se tornou um artigo dominante, configurando-se como importante produto econômico e fundamental elemento da dieta dos seus habitantes.

contraditoriamente - quanto do doce e do bolo de rua, do doce e do bolo de tabuleiro, da rapadura de feira rústica que o pobre gosta de saborear com farinha, juntando a sobremesa a alimento de substância" (FREYRE, 2007 [1939], p. 25). 
Esta culinária vem munida de uma cultura material pautada em peças tradicionais e regionais usadas no preparo dos quitutes. As casas-grandes e engenhos atuaram como principais ambientes onde esta culinária intercultural se desenvolveu, além dos conventos, que realizaram um importante papel na produção de uma doçaria fina e inventiva. Além do patrimônio material, incluímos também a imaterialidade patrimonial desta produção, que se reflete nas técnicas e conhecimentos gerados por um saber-fazer produzido nas cozinhas coloniais, responsáveis pelas misturas, adaptações e elaborações na arte de utilizar alimentos e temperos para a construção de novas receitas.

As cozinhas do período colonial constituíram-se verdadeiros laboratórios de experimentos interculturais, que possibilitaram misturas de heranças ibéricas, africanas e indígenas com distintos usos, técnicas e modos de fazer. Tais espaços eram ocupados por sinhás doceiras, mulatos boleiros e negros quituteiros - responsáveis pela construção de um vasto repertório de doces, bolos e quitutes. As cozinhas dos conventos portugueses também se tornaram espaços onde religiosas sem punham a recriar, inventar e experimentar receitas europeias utilizando ingredientes locais. Eram

[...] como laboratórios bem equipados de matéria-prima como ovos, leite, quer de vaca, quer de coco, frutas, cravo, canelas, vinhos, farinhas, açúcar, como eram então alguns dos conventos, para a especialidade em que a doçaria se constituiu dentro da cultura brasileira (FREYRE, 2007 [1939], p.177).

Os povos indígenas inseriram o uso do milho, da mandioca, do amendoim, das frutas da estação (sapoti, goiaba, caju, araçá) e da castanha. Utilizavam o mel para adoçar os alimentos que eram consumidos frescos. As índias, responsáveis por cozinhar nas aldeias, foram responsáveis pela elaboração de utensílios de cerâmica nas cozinhas

\footnotetext{
3 "Com a chegada dos portugueses e dos africanos escravos, temos um fenômeno curioso, porque as receitas dos doces eram de origem portuguesa, mas com uso de ingredientes locais e executados pelas mãos das escravas africanas. Já aí percebemos uma troca grande entre as diferentes culturas que aconteceu
}

com a produção de panelas, peneiras, vasilhas, pratos e outros utensílios.

A presença lusa nas terras nordestinas possibilitou diversas construções no âmbito da culinária. No caso da doçaria, houve a junção do açúcar com alimentos nativos, com as frutas tropicais e a mandioca, absorvendo neste intercâmbio diversas especiarias ${ }^{3}$. Os portugueses trouxeram influências mouriscas e africanas, bem como especiarias trazidas da Índia e da China. Foram responsáveis por inserir a cana-de-açúcar (proveniente da África) na paisagem, na economia e sobretudo na culinária brasileira, modificando definitivamente o paladar local. Os produtos provenientes da cana-de-açúcar foram responsáveis pela elaboração de um vasto repertório de doces (com o uso de ovos e frutas) e bebidas (em forma sucos, cachaças e licores), que continuam presentes no cotidiano do país.

Já os africanos, foram responsáveis por técnicas culinárias que modificaram diversas receitas portuguesas e indígenas. Por eles houve a inclusão de novos alimentos e novos modos de preparo. As negras reuniram conhecimentos sobre o uso de temperos, ervas, raízes, animais e frutas locais, produzindo uma culinária de forno e fogão. No período colonial, a presença de escravas e escravos nas cozinhas das fazendas, engenhos e as casasgrandes era constante. Foram os negros os principais responsáveis pelo desenvolvimento da doçaria de rua por meio do comércio ambulante de iguarias como bolos, mingaus, mungunzás, canjicas, arroz doce, pamonhas e outras iguarias. Os doces e bolos vendidos nas ruas eram feitos por escravas, senhoras brancas e ricas ou iaiás pobres (muitas vezes viúvas). Estes eram comercializados em tabuleiros, panelas, balaios e latas de doces vendidos por negros, negras ou moleques. Havia um apelo estético tropical, que demonstrava o cuidado das doceiras com a sua

de forma natural e que deu origem a uma quarta cultura, muito rica em sabores, texturas e histórias" (FERREIRA, 2003, p. 35). 
apresentação. Por isso, os doces e quitutes eram enfeitados e colocados nos tabuleiros forrados por toalhas limpas e alvas, conforme salienta Freyre em Casa Grande \& Senzala.

A tradição doceira no Brasil teve as mulheres como protagonistas. Conforme Freyre, as mulheres no período colonial (sinhás, cunhãs e mucamas) foram responsáveis por unir o paladar europeu ao tropical. Fato que resultou em uma notável produção de bolos, sorvetes, doces, mingaus, geleias, xaropes de frutas, licores, confeitos, papas, pastéis, cremes, compotas, dentre outras iguarias. Essa doçaria, conforme salientou o autor, resultou das contribuições das sinhás pálidas, das índias e cunhãs, negras doceiras e freiras quituteiras. Cada uma inseriu novos ingredientes, temperos, frutas e raízes, construindo uma culinária brasileira e multiétnica com uma estética própria.

\section{São Cristóvão: um reduto doceiro freyreano}

Em Sergipe, situado no Nordeste do Brasil, a presença da tradição doceira faz parte do cotidiano local, estando presente em mercados públicos, feiras populares, restaurantes, espaços turísticos, conventos, ruas da capital e cidades interioranas. Esta realidade pode ser encontrada com grande frequência em São Cristóvão, cidade histórica e primeira capital do estado, que representa importante reduto doceiro no estado. A doçaria sancristovense é produzida em diversos lares, em uma congregação religiosa, por meio de uma cooperativa e através de fábrica artesanal, responsáveis por produzir diariamente bolos, biscoitos, doces e licores caseiros para serem vendidos no comércio local e capital.

O município foi fundado em 1590, possui hoje uma população estimada em 85.814 pessoas (IBGE, 2014) ${ }^{4}$ e está situada no Sudoeste do estado, distante 26 quilômetros da capital, Aracaju. A cidade tem como principais atividades econômicas a

\footnotetext{
${ }^{4}$ População residente com data de referência de $1^{\circ} \mathrm{de}$ julho de 2014, publicada no Diário Oficial da União em 28/08/2014.
}

agricultura, notadamente com plantações de banana, laranja, mamão e feijão. A pecuária também se faz presente, por meio da criação de bovinos e a presença da piscicultura. A cidade é detentora de um importante acervo patrimonial formado por igrejas, casarões, conventos, museus e sobrados e foi reconhecida como Patrimônio Histórico e Artístico em âmbito nacional, segundo o IPHAN (Instituto do Patrimônio Histórico e Artístico Nacional). Em 2010 teve um de seus conjuntos patrimoniais, a Praça de São Francisco, declarada Patrimônio da Humanidade pela UNESCO.

Além do seu acervo arquitetônico, São Cristóvão possui um diversificado patrimônio imaterial formado por manifestações folclóricas, festas tradicionais e produção poética e musical. No município, a produção artesanal de quitutes, doces e licores também faz parte de seu repertório patrimonial, transformando-a em importante reduto doceiro sergipano. Na culinária sancristovense, o açúcar se misturou ao coco, ao milho, à mandioca e às frutas tropicais, construindo um diversificado repertório em que se destaca a produção de queijadas ${ }^{5}$ bricelets, bolos, cocadas, doces de frutas e biscoitos. O forno à lenha representa um importante elemento desta tradição, sendo o responsável por manter os segredos dessa herança cultural. Além do forno, há também a permanência do uso de diversos utensílios tradicionais, notadamente peneiras, tachos, colheres de pau, rapadores de coco, vasilhas e demais peças.

No Lar Imaculada Conceição da Santa Casa de Misericórdia são feitos os bricelets, biscoitinhos artesanais confeccionados em uma máquina de origem suíça, que são produzidos pelas religiosas e funcionários do espaço religioso. A receita foi trazida pelas irmãs beneditinas que viviam em São Cristóvão, cuja continuidade da tradição ficou a cargo das freiras do Lar Imaculada Conceição. A iguaria é intensamente consumida pelos visitantes e tem

\footnotetext{
5 Traz em sua receita a fusão da herança portuguesa e africana, pois, diferentemente do que o nome indica, o quitute é produzido com coco e não com queijo, sendo resultante de uma receita dos portugueses que foi reelaborada pelos escravos.
} 
colaborado na manutenção financeira do local. A iguaria "[...] tem a espessura de uma hóstia e de sabor suave, confeccionada com uma máquina especial que garante uma estética própria ao biscoito, sendo este resultante da mistura de ingredientes, como raspas de limão, farinha de trigo, suco de laranja, margarina, ovos e açúcar" (LEAL; COSTA; SANTOS, 2012, p. 1054).

No município podemos encontrar diversas residências que produzem bolachinhas, queijadas, bolos e cocadas durante todo o ano. No bairro Colônia Pintos destaca-se a fábrica Santa Helena, empreendimento familiar mantido pelo senhor Esmael, que produz diariamente bolos, bolachas, beijus, cocadas de forno e pamonha, cuja produção é amplamente vendida em São Cristóvão e Aracaju. O nome da fabriqueta é uma homenagem à Dona Maria Helena, patriarca da família que há mais de cinco décadas deu início a fabricação de iguarias típicas.

No município também podemos encontrar a Cooperativa de Doces Santa Salu COOPERUNIDOCE, situada no povoado Cabrita, que congrega diversas mulheres na produção de doces em calda e em pasta, geleias e balas. A iniciativa e liderança vem de Dona Tânia Santos, mais conhecida como Dona Santa Aninha, que através da cooperativa buscou melhorar a qualidade de vida das mulheres do povoado através da venda de doces diversos. Hoje o empreendimento conta cerca de 30 pessoas, com maquinários industriais doados pelo Instituto Afrânio Afonso Ferreira (IAAF), bem como assessoria empresarial do SEBRAE e da Universidade Federal de Sergipe.

\section{A cultura do doce na Festa de Nosso Senhor dos Passos}

Conforme Dantas (2006), a procissão de Nosso Senhor dos Passos, que acontece desde o século XIX em São Cristóvão-SE, não representa uma simples cerimônia religiosa, pois absorve uma série de manifestações tradicionais que constituem a paisagem sociocultural da festa. Trata-se de uma secular festividade do município, que reúne romeiros e religiosos de diversas cidades sergipanas e nordestinas. A comida, segundo a autora, apresentase como um dos principais elementos do comércio popular que se faz presente nos dias de procissão, capaz de evidenciar a relação entre o sagrado e o profano, o moderno e o tradicional, bem como práticas de caridade, consumo e solidariedade. Há a distribuição gratuita de suco, arroz doce e mungunzá, que ajudam a complementar a alimentação dos devotos. Desse modo, a alimentação, como forma de caridade, atua como um dos meios de exercício da fé e da devoção aosanto.

A variada oferta alimentar pode ser observada nas ruas, praças e residências sancristovenses como um universo de consumo que se aproxima dos tradicionais parques de diversão nordestinos, englobando barracas de comida, de artigos religiosos, brinquedos modernos e tradicionais, bem como brinquedos populares. Neste universo podemos encontrar a doçaria sancristovense, notadamente representada pelos doces em calda, compotas de frutas, bolos, cocadas, biscoitos e licores, que são comercializados em vários espaços da festa. Neste repertório, podemos identificar as queijadas e bolachinhas de goma, que representam uma antiga tradição local. Estas são resultantes de um saber-fazer feminino, que atua como uma importante fonte de complementação de renda para as mulheres que detém esse conhecimento. Como identifica Beatriz Góis Dantas (2006, p.57):

Durante a festa, aumentam as vendas da tradicional doçaria sancristovense, como as populares bolachinhas e queijadas, seus nobres e frágeis briceletes, estes saídos das mãos das freiras, transformados em sinais distintivos da culinária local, fazendo as delícias dos visitantes mais requintados.

Durante a festa, é possível encontrar um verdadeiro "corredor de queijadas e bolachinhas de goma", que se situa na Rua Tobias Barreto. Tais iguarias são vendidas em tabuleiros enfileirados, sendo consumidos pelos que ali circulam ou levados como lembrancinhas para amigos e familiares. Neste corredor, boa parte do que é comercializado é produzido por moradoras da Ilha Grande e do 
Povoado Pedreiras, ambos pertencentes a São Cristóvão, que alternam a produção doceira com o trabalho na maré. Algumas mulheres produzem especialmente para a festa e outras costumam comercializar durante todo 0 ano, seja por encomenda ou para as demais festas religiosas de Sergipe. As iguarias são vendidas em tabuleiros enfileirados, sendo consumidos em grande medida pelos que ali circulam. O apurado das vendas serve como uma complementação de renda individual de muitas doceiras.

$\mathrm{Na}$ tradição doceira da festa podemos encontrar Maria Madalena Santos, mais conhecida como Dona Madalena, uma senhora de 70 anos, moradora da Ilha Grande, mãe de doze filhos, aposentada, que além de doceira, representa uma importante liderança política em sua comunidade, atuando também como artesã, marisqueira e mestra do samba de coco local. Seu principal momento de venda ocorre na Festa de Nosso Senhor dos Passos. Durante a festa, a Rua Tobias Barreto se transforma em reduto das queijadas e bolachinhas de goma, concentrando diversas mulheres da Ilha Grande. Muitas delas aprenderam o ofício com Dona Madalena e hoje seguem ampliando sua renda individual e familiar com a venda das iguarias, transmitindo também às filhas, noras, amigas, vizinhas e parentes. Ao falar da tradição, Dona Madalena pontua: "A gente faz com amor, faz com gosto e aquilo rende. Porque, se a pessoa trabalhar com doce dá para comer $[. . .]^{6 "}$.

A referida doceira desempenha um relevante papel de manutenção desta tradição. Isso porque, na localidade em que reside, costuma transmitir às novas gerações tudo que aprendeu na arte de fazer bolachinhas, queijadas e doces de frutas. Durante o ano, a doceira costuma comercializar suas iguarias em alguns espaços do centro histórico de São Cristóvão, recebendo também encomendas que já foram para diversas cidades brasileiras $e$ estrangeiras. Ao se referir à queijada, principal iguaria de São Cristóvão, a doceira explica: "É tradição. Eu era pequena e já tinha tradição de queijada. [...] Essa tradição de queijada é antiga. Acho que tem bem uns cem anos".

\section{A Casa da Queijada de Dona Marieta}

Atualmente, um dos principais espaços de produção de São Cristóvão é a Casa da Queijada, cuja responsável é Dona Marieta. Trata-se do local de produção e comercialização de doces mais conhecido de São Cristóvão, estando localizado no coração do centro histórico da cidade. É lá que a doceira vive, produz e comercializa a famosa queijada, os licores de frutas, as bolachinhas, cocadas de forno e demais quitutes que fazem parte do patrimônio culinário da cidade. Todos os dias Dona Marieta acorda às três horas da manhã e, com a ajuda dos familiares, produz de segunda a sextafeira cerca de 300 a 320 queijadas por dia. Durante a produção, conta com a ajuda de quatro pessoas. A filha cuida das finanças, fazendo a contabilidade do empreendimento e as demais pessoas participam da etapa da elaboração dos quitutes. Há também outros familiares que fazem a venda dos produtos na entrada da casa.

Como bem salienta a interlocutora, trata-se de um ofício que exige a presença de outras pessoas, sobretudo pela complexidade das etapas de produção. Por isso, a presença familiar é tão recorrente, como ela mesma explica: "Porque uma pessoa só não dar conta, o trabalho é pesado mesmo, você tem que ter quem ajude. Você não procura quem faz queijada pra dizer, sou eu só. Não, não aguenta, não aguenta de jeito nenhum".

Dona Marieta começou vendendo na feira e festas do município e depois passou a vender em casa com a ajuda dos familiares. Seus principais consumidores são formados por moradores de Aracaju (capital do estado de Sergipe), pois, conforme a interlocutora, a população de São Cristóvão é na sua maioria carente e não tem poder aquisitivo para adquirir suas iguarias. Sua bisavó veio da África para o Brasil em um navio negreiro para ser escravizada e aprendeu a fazer a queijada entre a

\footnotetext{
${ }^{6}$ Entrevista realizada em 24 de fevereiro de 2013
} 
casa grande e a senzala. Escrava de uma família portuguesa foi parar na cozinha da casa grande, onde lá aprendeu várias iguarias da culinária portuguesa. Tal conhecimento foi posteriormente transmitido para as gerações seguintes.

A queijada, principal iguaria do município, traz em sua receita a fusão de herança lusa e africana, sendo resultante de uma receita portuguesa que foi reelaborada pelos escravos. Na casa-grande, os brancos faziam com queijo. "Os negros não tinham queijo. Tinham muito coco, açúcar e ovos. Nossa bisavó aprendeu a fazer em vez do queijo, o coco". Ainda de acordo com Dona Marieta, "[...] a de queijo é de Portugal, mas naquele tempo não tinha e o queijo não ia pra lá pra os escravos. O queijo era para o homem branco, pra casa grande". "É o doce da escravidão" definiu a doceira.

Seus familiares, provenientes da Bahia, aportaram na cidade de Capela/SE e a partir da sua avó vieram para São Cristóvão em busca de melhores condições de vida. Inicialmente se estabeleceram na cidade baixa, região pobre da cidade, margeada pelo rio, onde passaram por muitas privações, precisando inclusive pedir esmolas. Dona Marieta começou a fazer queijadinhas com sete anos vendo a mãe e a avó fazerem. Com 18 anos constituiu família e fez da queijadinha o seu sustento. "Viúva, graças a Deus", como ela mesma se identificou, teve um casamento sofrido, mas aguentou até o fim, porque segundo ela "mulher que casa não separa".

A doceira veio de uma família de seis irmãos (três homens e três mulheres) e todos trabalhavam no processo de feitura e venda da queijada. Ela conta que teve uma infância muito pobre, que se desenvolveu entre a pesca na maré e a venda do quitute para os pescadores. Naquela época quem comprava as queijadas eram pessoas pobres e hoje quem consome é rico, segundo a interlocutora. Sempre viveu da doçaria. Nunca trabalhou fora e nunca teve outra fonte de renda.

Filha mais velha de seis irmãos, Dona Marieta ajudou os irmãos a estudarem e formou todos os filhos. Ao perguntar sobre a importância da queijada em sua vida ela explicou: "Foi a melhor coisa que aconteceu na minha vida. Essa cultura me deu o direito de criar meus filhos. Criei meus filhos fazendo queijada. A queijada me deu o direito de ter três filhos formados. A menina é professora, o mais novo é médico". O terceiro filho é técnico em edificações. "O forno é o pai dos meus filhos. O forno é o pai de todo mundo. [é o pai] até de quem me ajuda [...] porque todo mundo participa do lucro. Eu não estou comendo sozinha", declarou ela. Explicou também que o filho médico sempre diz: "eu tenho uma mãe, mas meu pai é o forno".

Diante da história de vida de Dona Marieta, podemos perceber que muitas são as formas pelos quais as mulheres pobres buscam inserir-se no mercado de trabalho e uma delas é usando os conhecimentos adquiridos no seio familiar. Isso porque, historicamente, há muitas atividades femininas que escapam ao modelo tradicional de trabalho formal, sendo consequentemente desconsideradas pela lógica do capital (Silva, 2012). A culinária é uma dessas atividades, tendo importante função na constituição da identidade de suas produtoras.

A culinária está tradicionalmente vinculada à aprendizagem dos papéis femininos apreendidos ainda na infância, que muitas vezes suplanta o espaço doméstico e chega ao espaço público, contribuindo para dar visibilidade ao trabalho das mulheres. Trata-se de um modo de fazer artesanal que constitui uma importante fonte alternativa de renda para diversas mulheres no Brasil. Hoje, as doceiras atuam como guardiãs deste patrimônio cultural, por meio da manutenção e reinvenção de receitas que são transmitidas às novas gerações, absorvendo uma diversidade de ingredientes, modos de fazer e apresentar os doces.

Trata-se de um ofício tradicional muito ligado à constituição histórica do país, absorvendo uma diversidade de ingredientes e modos de produzir, que dialoga com novos ingredientes e formas de produzir, absorvendo reelaborações e criatividade de quem os produz. Por isso, concordamos com Freyre (1952) quando defende no Manifesto Regionalista de 
que a arte das mulheres de hoje está na adaptação destas heranças culinárias às condições de vida atuais.

No Nordeste brasileiro, a doçaria tradicional tornou-se um relevante mecanismo de renda feminina. A inserção das mulheres pobres no mercado de trabalho na região se dá de forma precária e reduzida, ocorrendo, sobretudo, por meio do mercado informal. Aspectos como instabilidade conjugal, pouca escolaridade e mudanças na estrutura familiar - que transformam as mulheres em chefes de família ou mães solteiras - atingem fortemente as mulheres pobres, dificultando o acesso ao mercado de trabalho (LAVINAS, 1996).

É importante salientar que a cidadania social feminina foi historicamente negligenciada, promovendo um atraso nos seus direitos políticos e civis. Conforme salienta Soares (2003), trata- se de uma cidadania parcial, frágil e tardia, que contribui cotidianamente para a exclusão e invisibilidade. Esta constitui uma realidade de difícil resolução, na medida em que há diversos fatores que colaboram para o confinamento do papel feminino ao ambiente doméstico e familiar. A autora sinaliza aspectos como a divisão sexual do trabalho, as questões simbólicas e culturais, bem como a relação entre público e privado como aspectos que distanciam a presença feminina do mercado de trabalho e da vida pública.

\section{Considerações finais}

Em suas obras Freyre antecede o conceito de interculturalidade, na medida em que evidencia a formação da identidade brasileira como resultado dos contatos interculturais e interétnicos. O escritor foi pioneiro em temas pouco abordados em seu tempo, tais como ecologia, estética, higiene, sexualidade, comida, vestuário, linguagem, arquitetura, moda, costumes e crenças do homem dos trópicos. Isso porque, o olhar etnográfico de Freyre se faz presente

\footnotetext{
7 "Nas terras de cana do Brasil essas tradições ganharam sabores tão novos, misturando-se com as frutas dos índios e com os quitutes dos negros, que tomaram uma expressão verdadeiramente brasileira.
}

nos modos de vida ordinária dos indivíduos comuns. Assim, mesmo a cultura tendo uma articulação com a história estrutural, é no dia-a-dia ordinário que está a chave para a compreensão da sociedade brasileira. São os pormenores da sociabilidade, bem como as práticas e costumes presentes no cotidiano que interessa o autor. A concepção de patrimônio cultural também se fez presente em seus escritos, quando, em suas interpretações considera como campo de estudo o simbólico, o imaterial, as festas, a culinária, a religiosidade, as referências étnicas, os saberes, fazeres e técnicas contidos no cotidiano.

Para o referido estudioso, a doçaria regional reúne arte, técnica e ciência permeando valores intrínsecos a nossa identidade, com implicações estéticas, sociais e culturais. Trata-se de um modo de alimentação e recreação dotado de uma etiqueta e um estilo, constituindo-se como objeto de estudo histórico, sociológico e etnológico. Isso porque, o açúcar adoçou diversos aspectos da vida brasileira, perpassando a economia, os hábitos e costumes nacionais ${ }^{7}$

As cores, formatos, cheiros, sabores e texturas. Os rituais de elaboração, oferecimento e consumo. A estética das comidas e espaços comensais; as formas de preparo e as soluções técnicas orientadas por heranças e trocas culturais; os utensílios desta etnoculinária brasileira, que abarca desde as louças refinadas europeias aos enfeitados tabuleiros à moda afro-brasileira (LODY, 2011). Todos estes elementos fizeram parte das interpretações de Freyre, construtor de uma escrita sensível, artística e afetuosa sem deixar de ser científica.

\section{Referências}

1 ALCÂNTARA, Clênio Sierra de. "Santo de casa faz milagre, sim! - O retratista Gilberto Freyre posto numa moldura por Raul Lody". In: Lody, Raul: Caminhos do Açúcar. Rio de Janeiro: Topbooks, 2011, pp.13-20.

Não há arte mais autenticamente brasileira que a do doce e a do bolo dos engenhos do Nordeste e do extremo Norte" (FREYRE, 2007, p. 66). 
2 DANTAS, Beatriz Goes. "Entre o sagrado e o profano". In: Vieira, Márcio José Garcez. Senhor dos Passos em todos os passos. Aracaju: Gráfica J. Andrade, 2006, pp.55-59.

3 FERREIRA, Paola Biselli. "O doce brasileiro como identidade cultural". In: Anais do 'Congresso Internacional de Gastronomia - Mesa Tendências 2013 Senac São Paulo, 2013, pp. 27-40.

4 FREYRE, Gilberto. Açúcar: uma sociologia do doce, com receitas de bolos e doces do Nordeste do Brasil. 5a Ed. São Paulo: Global, 2007 [1939].

5 HERNÁNDEZ, Jesus Contreras; ARNÁIZ, Mabel Gracia. Alimentación y cultura: perspectivas antropológicas. Barcelona: Ariel, 2005.

6 LAVINAS, Lena. As Mulheres no Universo da Pobreza, o Caso Brasileiro. Revista de Estudos Feministas, n.02, 1996, pp. 464-479.

7 LEAL, Rosana Eduardo da Silva; COSTA, Sidjan Sousa Peixoto; SANTOS, Marcelo Carvalho. "O Doce Patrimônio de São Cristóvão". In: Giovanni Seabra. (Org.). Comunidades, Natureza e Cultura no Turismo. João Pessoa: Editora Universitária da UFPB, 2012, pp. 1058-1069.

8 LODY, Raul. Caminhos do Açúcar. Rio de Janeiro: 2011, Topbooks.

9 SILVA, Márcia Alves da. "Discutindo Gênero através do trabalho artesanal". In: IX ANPED SUL. Seminário de Pesquisa em Educação da Região Sul, 2012.

10 SOARES, Vera. "A construção da cidadania fragilizada da mulher". In: Emilio, M., Teixeira, M.; Nobre M., Godinho, T. (orgs). Trabalho e cidadania ativa para as mulheres: desafios para as Políticas Públicas. São Paulo: Coordenadoria Especial da Mulher, 2003, pp.89-100. 